\title{
LETRAMENTO ESTATÍSTICO E O BANCO DE DADOS DOLLAR STREET: UMA PROPOSTA PARA OS ANOS INICIAIS DO ENSINO FUNDAMENTAL
}

\author{
STATISTICAL LITERACY AND THE DOLLAR STREET DATABASE: A \\ PROPOSAL FOR THE EARLY YEARS OF THE ELEMENTAR SCHOOL
}

\author{
Roberta Schnorr Buehring \\ Prefeitura Municipal de Florianópolis \\ Universidade Federal de Santa Catarina - UFSC \\ robertaschb@gmail.com \\ Regina Célia Grando \\ Universidade Federal de Santa Catarina - UFSC \\ regrando@yahoo.com.br \\ Ana Paula Canavarro \\ Universidade de Évora - Portugal \\ apc@uévora.pt
}

\section{Resumo}

Acreditamos que o letramento estatístico é necessário para a inserção na cultura letrada que marca nossa sociedade e que este se pode desenvolver ao longo da vida, tendo início nos primeiros anos da escolaridade das crianças. Este artigo tem por objetivo compreender como desenvolver o letramento estatístico de forma que as crianças sejam protagonistas frente aos dados e estabeleçam conexões entre os dados da realidade e suas vidas. Para tal, refletimos a respeito do letramento estatístico à luz de diversos autores e narramos as experiências das crianças com o banco de dados interativo virtual Dollar Street, realizadas em uma sala de aula de segundo ano do Ensino Fundamental. Os dados foram recolhidos a partir de vídeo gravações da prática de sala de aula e deram origem a diários de campo que costuraram teorias ao vivido e aprendido com as crianças. O estudo mostra que o letramento estatístico não é um ponto de chegada, mas um caminho trilhado de forma conectada com as linguagens escrita, oral e digital. Mostra também que crianças e professoras, ao explorar livremente dados multivariados sobre o mundo, podem se tornar pessoas dispostas a ler, escrever, criar, imaginar e até mesmo se indignar.

Palavras-chave: letramento estatístico, anos iniciais do Ensino Fundamental, banco de dados Dollar Street, dados multivariados

\begin{abstract}
We believe that statistical literacy is necessary for being integrated in the literate culture that marks our society and that it can develop throughout life, starting in the early years of children's schooling. This study aims to understand how to develop statistical literacy so that children are protagonists when
\end{abstract}


dealing with data and they are able to establish connections between real data and their lives. To achive this aim, we reflected on statistical literacy in the light of several authors and narrated the children's experiences with the virtual interactive database Dollar Street, carried out in a second-year elementary school classroom. The data were collected from video recordings of classroom practice and gave rise to field diaries that sewed theories into what was lived and learned with the children. The study shows that statistical literacy is not a point of arrival, but a path traced in a connected way with written, oral and digital languages. It also shows that children and teachers, when exploring freely multivariate data about the world, can become people willing to read, write, create, imagine and even indignate themselves.

Keywords: statistical literacy; early years in primary school, Dollar Street database, multivariate data.

\section{INTRODUÇÃO}

Nascemos e vivemos dentro de uma cultura de números, letras e símbolos que dão sentido a tudo, permitem a comunicação e as mais diversas expressões humanas.

Cada vez mais, o mundo pede que saibamos lidar com dados, para que não sejamos meros receptáculos de estatísticas. No entanto, para ser um leitor ativo que compreende, confere a fonte da informação, que reflete sobre como os dados foram apresentados, suas intenções e os seus contextos, é preciso ter conhecimentos e também disposições que requerem um longo caminho de aprendizagem. É nesse ponto que, no lugar de professoras e pesquisadoras, nos questionamos: como trilhar os caminhos do letramento estatístico desde o início da escolaridade de modo que as crianças sejam ativas frente aos dados e estabeleçam conexões entre a realidade do mundo e da sua vida?

$\mathrm{O}$ artigo que apresentamos é parte da pesquisa de doutorado da primeira autora, professora dos anos iniciais do Ensino Fundamental e de suas supervisoras de pesquisa, segunda e terceira autoras, ambas pesquisadoras e professoras formadoras de professores. Neste texto, refletimos a respeito do letramento estatístico à luz de diversos autores e narramos nossas experiências com o banco de dados interativo virtual Dollar Street, em uma sala de aula de segundo ano do Ensino Fundamental.

Os dados foram produzidos numa escola pública municipal de Florianópolis na qual a primeira autora atuou como professora de 24 crianças com idades entre 7 e 8 anos no ano de 2019. A pesquisa tem característica longitudinal, pois acompanhou uma mesma turma de crianças durante o primeiro, segundo e terceiro ano de escolaridade do Ensino Fundamental e as práticas aqui narradas dizem respeito a uma parte do segundo ano (que ocorreu em 2019). A gravação das aulas em vídeo permitiu produzir diários de campo narrativos e reflexivos. A forma de escrita e a pesquisa são narrativas, pois dão significado a experiências vividas pela 
primeira autora atuando em uma sala de aula com crianças.

Iniciamos a narrativa olhando para o letramento estatístico como um dilema, um lugar de intersecção entre a estatística e o letramento que requer conhecimentos básicos de estatística, bem como a capacidade de expressar tal compreensão em palavras - e não fórmulas ou cálculos (Watson, 2006) - da cultura letrada. Pensamos que na escola temos um certo tipo de dificuldade com o lugar de fronteira, principalmente quando tratamos de estatística, que a princípio parece uma ciência inacessível para crianças.

Num segundo momento apresentamos a base de dados Dollar Street como fonte de informação e problematização do mundo e de como as pessoas vivem no mundo. A base de dados usa fotografias, ícones, cores, localização no mapa e texto para mostrar como podem ser as particularidades e generalidades do mundo. Nós a definimos, a partir de Engel (2017), como uma base de dados multivariados.

Em seguida, levamos este mesmo banco de dados virtual para a exploração de uma turma de crianças de segundo ano, entre sete e oito anos de idade, do Ensino Fundamental numa escola pública municipal de Florianópolis - SC. A partir dos diálogos de sala de aula, atentamos para as maneiras que as crianças lidam com o dilúvio de dados (BEN-ZVI, 2018), como categorizam e classificam dados e como estabelecem suas lentes de dados (ENGLISH, 2013).

\section{LETRAMENTO ESTATÍSTICO, UM LUGAR DE FRONTEIRA}

Os dados influenciam na forma como o mundo se organiza e em como o vemos com base em argumentos, evidências e estatísticas. Hoje, e cada vez mais, o cidadão tem acesso a qualquer tipo de informação, inclusive as informações estatais que estão disponíveis em plataformas abertas na rede de computadores. Ao mesmo tempo, a e-democracia possibilita que todas as pessoas publiquem qualquer tipo de informação e que tirem suas próprias conclusões, sejam elas baseadas em dados ou não.

Mesmo em tempos de excesso de dados, Engel (2017) afirma que a desinformação ou a não compreensão da informação continuam imperando, porque as notícias falsas são capazes de desestruturar a participação democrática e ameaçar nossa forma de vida. Por isso, mais do que nunca, saber escolher a informação, compreender a fonte e a veracidade dos dados são questões básicas de letramento estatístico. Para Engel (2017), uma educação para a cidadania 
baseada na análise e pensamento crítico sobre evidências é o melhor remédio para um mundo guiado por notícias falsas ou alheio aos fatos. O autor explicita que há muito a ser trabalhado em Educação Estatística:

Se esperamos que nossos alunos se tornem cidadãos ativos que possam entender as estatísticas publicadas na esfera pública (pela mídia, produtores oficiais de estatísticas, etc.) e checagem de fatos por conta própria, eles precisam de uma sólida base de conhecimento que inclua conhecimento de contexto, matemática básica, familiaridade com (pelo menos) estatísticas elementares e familiaridade com ferramentas gráficas e numéricas apropriadas para representação de dados, juntamente com uma capacidade de pensamento crítico e uma disposição para se envolver com evidências. (Engel, 2017, p. 47. Tradução livre das autoras)

Antes de pensar no que é letramento estatístico precisamos pensar sobre que tipo de coisa estamos lendo quando nos deparamos com dados, que tipo de leitura e de comunicação estamos falando quando usamos o termo letramento estatístico.

Assim, encaramos letramento e estatística como uma inevitável e urgente junção de duas palavras que são como as peças de um puzzle, resultam em letramento estatístico, termo que não pode ser lido com maior ênfase nesta ou naquela palavra. Quando unimos duas peças de um puzzle é possível que a linha de fronteira que as une (ou separa) se torne invisível ao olharmos para o puzzle como um todo. Talvez se entrarmos à fundo na estatística como ciência de dados e no letramento como processo de inserção na cultura escrita, seja difícil perceber onde é que eles se unem, por isso, letramento estatístico é esse lugar de fronteira e de interseção.

Batanero, Díaz, Contreras e Roa (2013) apontam para esse lugar quando falam em cultura estatística como necessidade para que as pessoas participem de atividades de leitura e interpretação de informações disponíveis nas mídias bem como de situações cotidianas. É a capacidade humana de assumir uma atitude crítica frente a informação, e para isso são necessários conhecimento da linguagem estatística e suas ideias fundamentais. Baseados em estudos de currículos de diversos países, Batanero e colegas (2013) sugerem as seguintes ideias fundamentais para o ensino do sentido estatístico: dados, gráficos, variabilidade aleatória, distribuição, associação e correlação, probabilidade, amostra e inferência. O sentido estatístico seria o lugar de fronteira entre raciocínio e estatística, a união da cultura e raciocínio estatísticos e, para os autores, precisa ser trabalhado progressivamente desde os anos iniciais de escolaridade até a universidade (Batanero et al, 2013).

Batanero e colegas (2013) consideram que o trabalho por projetos é a melhor forma de 
promover este desenvolvimento porque no lugar de introduzir conceitos ou levar uma tarefa com um problema fictício, o professor oportuniza as diferentes fases de uma investigação estatística, com o planejamento de um problema, tomada de decisões sobre os dados a serem usados, análise dos dados e conclusões sobre o problema desenvolvido (BATANERO et al, 2013). Com os projetos, os alunos podem desenvolver atitudes próprias da cultura e raciocínio estatístico como criatividade, espírito crítico e imaginação. O desenvolvimento de projetos também inclui conhecimentos estratégicos e aumenta a motivação dos estudantes.

Para Gal (2002), o letramento estatístico é uma habilidade-chave esperada dos cidadãos nas sociedades carregadas de informação e é frequentemente apresentada como um resultado da escolaridade e como um componente necessário do numeramento ${ }^{1} \mathrm{e}$ alfabetização. Afirma que letramento estatístico não seria apenas uma habilidade, mas um conjunto de práticas culturais com as quais as pessoas se envolvem (GAL, 2002). O autor afirma que não há consenso entre pesquisadores para determinar quais são as habilidades estatísticas necessárias para um adulto e que as pesquisas apontam para "o que" a escola deve ensinar, mas não dizem o que uma pessoa precisa saber para ser considerada estatisticamente letrada (GAL, 2002). Assim, Gal (2002) propõe uma conceitualização de letramento estatístico retratada por ele como "a capacidade de interpretar, avaliar criticamente e se comunicar sobre informações e mensagens estatísticas" (p.1). Argumenta que o comportamento estatisticamente letrado envolve a ativação conjunta de cinco bases de conhecimento: alfabetização, estatística, matemática, contexto e crítica; que atuam juntamente com um conjunto de disposições de apoio e crenças facilitadoras (GAL, 2002).

Gal ainda lista cinco categorias para considerar "adultos" letrados estatisticamente e observamos que também são caminhos pelos quais as crianças precisam passar para serem estatisticamente letradas, pois afinal o seu ensino inicia-se cada vez mais cedo (BATANERO et al, 2013). Gal (2002) explicita sua preocupação com a ação de consumidor estatístico da qual todos, sem distinção de idade, fazemos parte ao ler um anúncio, ao assistir televisão, etc. São contextos da vida, de áreas diversas aos quais ele denomina contextos de leitura que se apresentam de três formas: através do texto (escrito ou oral), números e símbolos e exibições gráficas ou tabulares e, ainda, combinados, como é frequente.

Ainda é importante considerar que as categorias de Gal (2002) para o letramento

\footnotetext{
${ }^{1}$ Tradução livre das autoras para "numeracy", que em português europeu se traduz por "numeracia".
} 
estatístico são inter-relacionadas e até mesmo sobrepostas, há um movimento, uma troca de lugares, passos que se galgam ao longo de uma caminhada sem que seja necessária uma ordem pré-estabelecida. Ele as separa para fins de compreensão e análise e afirma que não é necessário possuir todas elas para que se possa lidar efetivamente "com tarefas interpretativas em todas as leituras e contextos de escuta" (GAL, 2002, p. 20).

1. Saber por que os dados são necessários e como eles são produzidos

2. Familiaridade com os termos e ideias básicos relacionados à estatística descritiva

3. Familiaridade com exibições gráficas e tabulares e suas interpretações

4. Noções básicas de probabilidade

5. Saber como chegar a conclusões ou inferências estatísticas

A primeira categoria para conhecimento estatístico de Gal diz respeito a saber como os dados são produzidos e como nós os compreendemos a fim de formar leitores estatísticos. Para tanto, é preciso que os leitores também passem por muitas experiências de produção de dados. Para compreender que os dados não aparecem como mágica, é preciso ir em busca deles, passar por situações de decisão de instrumentos de recolha de dados, pensar sobre quais os instrumentos possíveis, quais os mais eficazes, qual a população, amostra, etc.

A segunda categoria para o letramento estatístico (GAL, 2002) trata de conhecer os termos estatísticos, que podem ser desconhecidos ou ambíguos até mesmo para os adultos. Muitas vezes, pessoas que divulgam dados também não tem conhecimento dos termos corretos e os utiliza de maneira contraditória; é possível que isso ocorra por desconhecimento ou até mesmo para provocar uma reação no leitor. Gal (2002, p. 21) argumenta que é papel da escola promover um "ambiente comunicativo heterogêneo em que seja preciso lidar com diferentes mensagens estatísticas, isso para que os estudantes possam questionar sobre as palavras que não compreendem e usar o vocabulário estatístico de modo que possam ter uma atitude crítica".

$\mathrm{Na}$ terceira categoria, afirma que é preciso ter familiaridade com representações gráficas e tabulares e compreender que um mesmo dado pode ser representado e lido de diversas maneiras. Sugere que o leitor estatístico seja capaz de realizar uma leitura de dados conforme sugere Curcio (1994): ler os dados, ler entre os dados e ler além dos dados.

Gal (2002) expõe como quarta categoria básica para o letramento estatístico a necessidade de compreensão da probabilidade e a linguagem do acaso: como as ideias de aleatoriedade, estimativa, risco e chance são comunicadas. Destaca que as ideias são necessárias para o letramento, mesmo que seja de forma intuitiva e subjetiva. 
Como quinta categoria, Gal (2002) aponta a necessidade de saber como chegar a conclusões ou inferências estatísticas. Mesmo na condição de consumidor de dados, é preciso saber como se chega a resultados e inferências para compreender que os dados podem ser passíveis de diferentes conclusões e então poder tomar uma postura crítica.

Além de estar relacionado a cinco bases do conhecimento, o letramento estatístico também depende de três elementos que são "conhecimento contextual, habilidades críticas e disposições necessárias" (GAL, 2002, p. 21). A questão contextual foi defendida por Moore (1990), quando argumentou que o contexto motiva procedimentos; os dados devem ser vistos como números com um contexto e, portanto, o contexto é a fonte do significado e a base para a interpretação dos resultados obtidos. Assim, os contextos são inseparáveis da estatística, desde o contexto e as intenções de quem os produz até os de quem os lê.

De acordo com Engel (2017), os dados são multivariados, isso quer dizer que estão cercados de fatores, de influências envolvendo causas e consequências que não podem ser compreendidas de maneira isolada. Ainda é preciso saber que os dados multivariados não se apresentam de forma "comportada", em gráficos e tabelas bem desenhados tal qual nos livros escolares, porque eles são correlacionados, interativos e dinâmicos. Ler os dados multivariados é também compreender como as leituras errôneas acontecem e perceber como notícias falsas são produzidas a partir de dados factuais, que envolvem uma cultura de produção de pós-verdades (Engel, 2017). Os dados multivariados podem-se apresentar de diversas maneiras, com visualizações inovadoras que relacionam os dados ao tempo, à localização, à economia, cultura e realidade social e, por serem dinâmicos, permitem inúmeros formatos de visualização e comparação.

Para ler dados é necessário estar aberto ao mundo e suas características multifacetadas e, ao mesmo tempo, aproximar-se e envolver-se com os dados pois a sua leitura envolve a identidade do leitor e o seu contexto: pessoas diferentes podem ler os mesmos dados de maneira distinta, ou a mesma pessoa, em momentos diferentes, pode ler os mesmos dados de maneira distinta.

Outra questão importante apontada por Gal (2002) para o letramento estatístico são as “disposições” que implicam numa forma de interpretação que não é passiva, mas que depende de uma ação. Quer dizer que não é possível chamar de letrada estatisticamente a pessoa que possua as cinco bases para o conhecimento estatístico mas que não se incline a ativá-las: é 
preciso estar disposto a opinar, julgar, interpretar e compartilhar, no diálogo. O termo “disposições” é usado por Gal (2002, p. 18) como um "rótulo agregado conveniente para três itens relacionados, mas distintos conceitos, postura crítica, crenças e atitudes, essenciais para a alfabetização estatística". Como são três conceitos interconectados, o autor opta por denominá-los com apenas uma palavra e descrevê-los de forma conjunta.

As atitudes podem representar, por exemplo, sentimentos em relação aos objetos (gosto, não gosto) que quando se mantém como opiniões individuais, e juntamente de questões culturais, transformam-se em crenças. Por isso, é preciso que desde cedo as crianças se sintam capazes de levantar hipóteses, conjecturar e pensar estatisticamente. É preciso que se sintam em condições de avaliar e sustentar sua motivação para ações críticas e para isso devem desenvolver uma visão positiva de si mesmo como indivíduos que, frente a diferentes representações estatísticas, se sintam capazes (Gal, 2002).

Lopes e Cox (2018) falam sobre a necessidade de proporcionar uma educação em que as crianças tenham experiências contrárias às "agressões" à cultura infantil, "que roubam o prazer das crianças de descoberta, observação sobre os movimentos da natureza, das relações da vida com os colegas, da alegria de imaginar e criar, de agir de maneira diferente" (p. 79). As crianças são capazes de ter o seu próprio olhar sobre os dados, de produzir, criar e imaginar a partir dos dados. Isso não quer dizer que são apenas "consumidores", podem ser sim, seres ativos em relação aos dados, embasados em suas realidades e não em nossa própria maneira adulta de conhecer (LOPES; COX, 2018).

Até aqui, dialogamos com muitas vozes sobre o letramento estatístico, elas se complementam e nos apontam os caminhos pelos quais pretendemos andar. Todas elas, em uníssono, nos convencem sobre a necessidade e emergência da Educação Estatística. As vozes dos autores ainda nos dizem o quão complexo é o letramento estatístico por estar enredado em muitos outros conceitos, contextos e por depender de disposições pessoais que precisam ser desenvolvidas. O que ensinar para as crianças sobre uma coisa que pode ser tão complexa e exigir conhecimentos dos quais elas ainda não são capazes? Como proporcionar que se criem disposições para um letramento estatístico constante, ao longo da vida do estudante?

\section{BANCO DE DADOS DOLLAR STREET NA SALA DE AULA}

Atentas a questões que envolvem o conhecimento estatístico, o letramento e a infância, 
fomos ao segundo ano do Ensino Fundamental, turma que já conhecíamos e com a qual já havíamos trabalhado um ano antes com coleta de dados, gráficos e tabelas sobre suas próprias características e gostos. A inserção das crianças no contexto estatístico nas aulas de 2019 tiveram especial conexão com o mundo, pois os dados estatísticos isolados são empobrecidos (Makar, 2018). Buscamos um banco de dados multivariados que fosse acessível a crianças de sete e oito anos de idade que estão em processo de alfabetização. A característica desses dados é a grande quantidade de informações disponíveis a partir de imagens, cores, mapas, localizações, texto escrito e linguagem icônica, acessíveis de forma interativa e livre na internet.

O banco de dados virtual Dollar Street é de acesso gratuito e pode aceder-se em https://www.gapminder.org/dollar-street/matrix. Trata-se de um banco de dados que utiliza imagens de cerca de 300 famílias que são uma amostra proporcional da população mundial, levando em consideração o continente em que vivem e o seu nível de consumo. As imagens apresentam até 130 categorias diferentes de objetos e características de cada uma das famílias e são organizadas em uma rua linear horizontal: em cada casa da rua mora uma família. $\mathrm{Na}$ rua, imaginam-se morando pessoas do mundo todo e o que determina seu local de moradia na rua é a sua renda mensal familiar: num extremo da rua moram as pessoas com poder de consumo mensal mais baixo e, no outro extremo, com o mais alto.

Figura 1 - Dollar Street

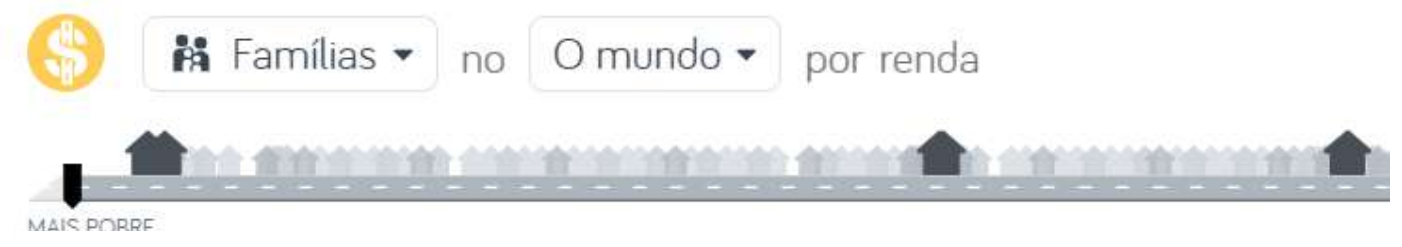

Fonte: https:// www.gapminder.org/dollar-street/

O valor de consumo de cada família é medido em dólares por mês atribuídos a cada casa. O cálculo para chegar ao valor de consumo familiar está relacionado ao consumo disponível para cada adulto da família e o total é dividido para chegar ao que chamam de equivalente adulto. Os dólares americanos são ajustados em cada país pela paridade do poder de compra. Assim, estão representados no extremo esquerdo os moradores em situação de miséria (nível 1), que dispõem em média de dois dólares por dia e que somam mais ou menos um bilhão de pessoas da população mundial. Do outro extremo, os moradores do nível 4 , 
consumidores ricos que ganham mais de 32 dólares por dia. No meio, está a maioria dos moradores dos níveis 2 e 3, que são famílias com renda entre 4 e 30 dólares por dia e representam, em números absolutos, 5 bilhões de pessoas. A amostra das famílias que compõem a Rua Dólar também é proporcional à população mundial, levando em consideração a população por continente: dos sete bilhões de habitantes mundiais, 1 bilhão são americanos, 1 bilhão são africanos, 1 bilhão são europeus e 4 bilhões são asiáticos (arredondando os números).

Segundo Rosling (2020), um dos Figura 2 - Algumas das categorias do Dollar Street criadores da Rua Dólar, nós precisamos de categorias para viver no mundo, pois não é possível olhar para todos os detalhes de tudo. Por isso, as imagens do banco de dados se apresentam em categorias sendo que ao mesmo tempo em que é possível compreender em que situação vive a população mundial, também se pode entrar na casa de qualquer uma dessas famílias com um simples "click" e fazer uma visita, ver

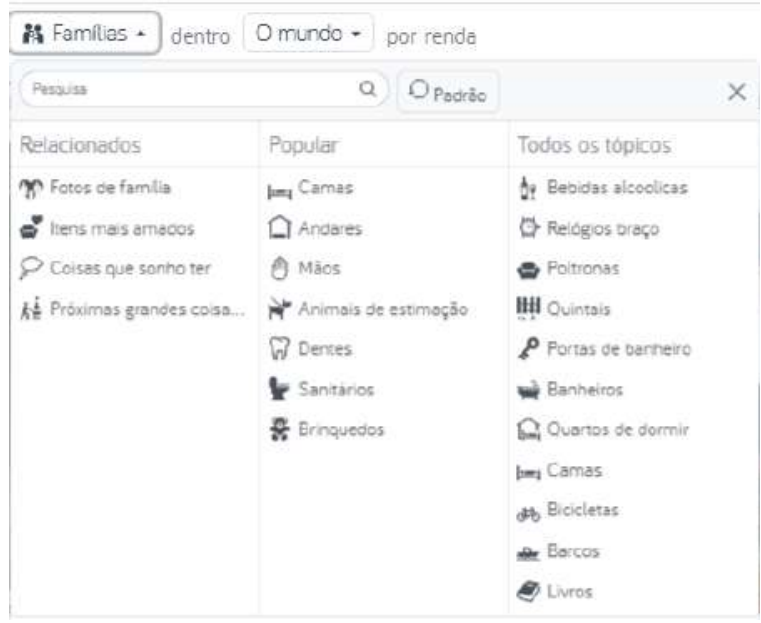

Fonte:https://www.gapminder.org/dollar-street/ imagens do que as pessoas da família comem, onde dormem, seus materiais de escrita, de higiene, brinquedos, meios de transporte, animais de estimação e muitos outros objetos que revelam como as pessoas vivem.

Rosling (2020) afirma que temos o instinto de generalização e categorização que levam a raciocinar de forma ampla e é desse modo que o Dollar Street se organiza. Ir e vir nessas categorias e localizações nos permite a consciência do que estamos escolhendo para ver e isso é essencial para navegar pelos dados não apenas olhando imagens, mas com o pensamento em alerta.

Rosling (2020) acredita ser importante olhar para o geral e o particular e estar atento pois há "generalizações amplas demais que podem facilmente se esconder atrás de boas intenções" (p. 75). Selecionamos a ilustração que segue na Figura 3 para mostrar o quanto uma visualização conjunta de imagens do Dollar Street pode ativar uma análise geral e particular ao mesmo tempo. 
Figura 3 - Saídas de água das casas do Dollar Street

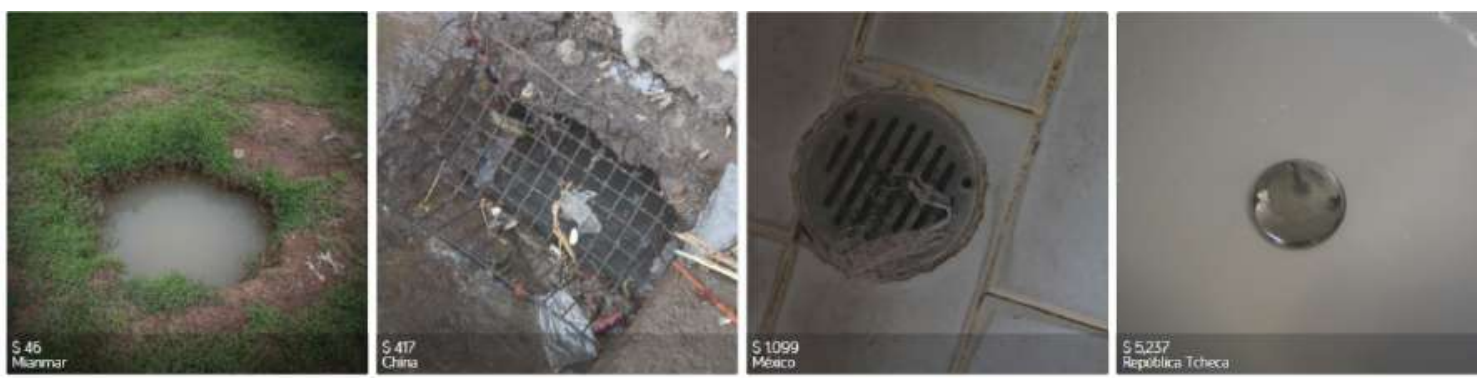

Fonte: https://www.gapminder.org/dollar-street/?topic=water-outlets

A Figura 3 mostra como pode ser a saída de água de casas relativas a quatro níveis de rendimento diferentes. É uma generalização, pois cada imagem representa uma população enorme de ralos no mundo, esta é apenas uma amostra que generaliza características de ralos dos níveis 1 a 4 . Ao mesmo tempo, são imagens particulares de um pequeno detalhe da casa que pode trazer consigo histórias sobre as condições de saneamento básico em que vivem os moradores. Imagens como estas podem dizer muito, podem contar histórias e permitem que compreendamos como é viver em cada um desses níveis, coisa que números ou gráfícos não são capazes de dizer.

Rosling (2020) aponta que as estatísticas podem medir a qualidade da saúde, moradia, educação e inumeráveis fatores de toda a sociedade, mas é preciso ver por trás dos números e compreender o que eles nos contam sobre a vida das pessoas. As imagens permitem uma conexão com a realidade, permitem imaginar histórias de vida a partir "do que conheço", mesmo quando olho para uma família de outro lugar, "que não conheço". Com o Dollar Street somos convidados a "olhar para as estatísticas por trás das histórias individuais, e também a olhar para as histórias individuais por trás das estatísticas. O mundo não pode ser compreendido sem números. E não pode ser compreendido só com números" (ROSLING, 2020, p. 139).

Outro diferencial do Dollar Street é que as famílias falam da sua satisfação ou não de viver onde e como vivem e, também, de seus sonhos, o que possibilita nos colocarmos no lugar daquela família compreendendo um pouco de seus sentimentos. No Dollar Street o usuário escolhe se quer olhar para a localização da renda, na linha horizontal da rua, para a localização geográfica no mapa, se pretende escolher uma categoria para ver no mundo todo, num continente ou país. A quantidade de dados é imensa e as combinações possíveis são ainda maiores, tudo depende das lentes de dados de cada um (ENGLISH, 2013). 
Diante de tantos dados, é fácil se perguntar: o que eu posso fazer com isso? Ou melhor: como ou porque levar esses dados para as crianças? O que as crianças vão compreender e "ver" no Dollar Street? Porque levar tantos dados e não levar um gráfico pronto, com colunas mostrando a renda mundial, por exemplo? Qual o sentido disso?

Seguimos com reflexões sobre como foi caminhar pela Rua Dólar com as crianças, buscando o entendimento e leitura do mundo a partir do exercício da postura crítica e de se conceber como pessoa capaz de falar sobre os dados.

\section{“OLHA AÍ 'CUMPADE', COISAS, CASAS, BRINQUEDOS, COMIDA...”: EXPLORANDO O LETRAMENTO ESTATÍSTICO COM DADOS MULTIVARIADOS}

Nossa primeira aula com a navegação do Dollar Street com a turma de segundo ano do ensino fundamental, dirigida pela primeira autora do artigo, foi marcada pelo desejo das crianças encontrarem Florianópolis (cidade na qual moram). Este desejo não era uma simples curiosidade de como a base de dados mostraria a sua cidade mas com a vontade intrínseca de estarem representadas. Mesmo navegando por muitos lugares do mundo, a necessidade das crianças de se verem representadas no Dollar Street continuou presente em vários momentos. As crianças perceberam que o mundo mostrado no Dollar Street não era uma "amostra" qualquer e não era "o" mundo. As generalizações da Rua Dólar deixavam de fora as coisas que elas viam todos os dias e isso talvez tenha tornado o banco de dados um tanto abstrato para elas, em alguns momentos. Então, se socorriam do Google Maps para entender ou ver o que o Dollar Street não permitia. Isso evidencia como lidaram bem com o dilúvio de dados (BEN-ZVI, 2018): foram procurar coisas que a base de dados não mostrava, a fim de agregar, complementar o que para elas eram limitações da Dollar Street.

Nossa intenção não foi impor o mundo da Dollar Street, mas ampliar o campo de visão sobre os dados. Gostaríamos que as crianças percebessem que os dados são necessários (GAL, 2002) para uma certa leitura de mundo, para entender o mundo. Com o Dollar Street, acreditamos que as crianças poderiam se sentir capazes, dispostas (GAL, 2002) e interessadas por olhar e descobrir o mundo pelos dados. Foram intenções pertinentes porque as crianças ficaram empolgadas com a possibilidade de conhecer particularidades do mundo a partir dos dados e foram autônomas em suas descobertas. 
No entanto, a representação no modelo da rua linear horizontal não foi significativa num primeiro momento, apenas escolheram as famílias pelas imagens, pelo mapa mundi (figura7) ou a lista de categorias (figura 2).

Figura 4 - Mapa mundi no Dollar Street

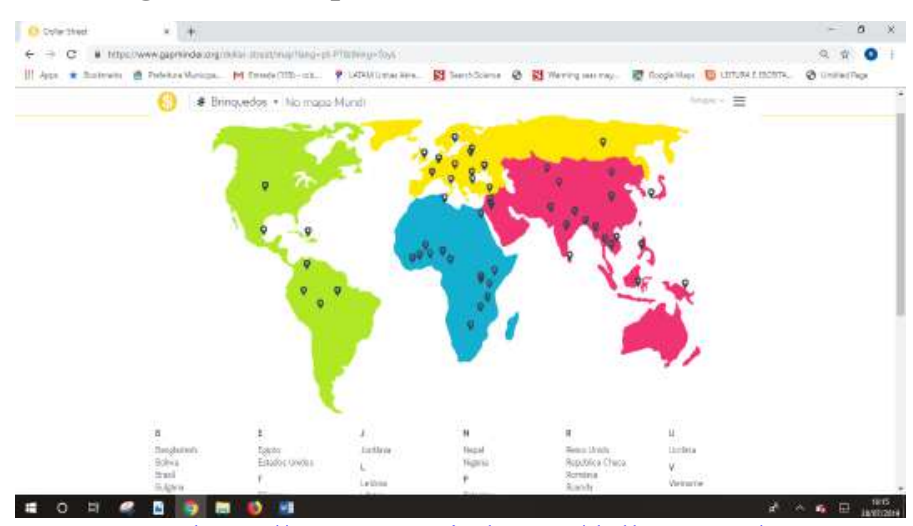

Fonte: https://www.gapminder.org/dollar-street/map

A representação gráfica da rua com as setas para escolher um intervalo de casas na rua foi quase ignorada pelas crianças, assim como o valor monetário. Talvez naquele momento a rua exigisse uma mudança de representação intransponível para quem vê e explora o globo terrestre no Google Maps, para quem anda pelos espaços complexos do mundo, por morros e baixadas, por curvas e esquinas. Talvez a representação da rua planificada, linear e delimitada seja o modo que nós adultos aprendemos a conceber o mundo, modo pelo qual as crianças que exploram e veem suas curvas e dimensões (que saem do plano) não compartilham. Ou, ainda, é possível que simplesmente o valor monetário e a organização em forma de rua fizesse pouco sentido para as crianças e então suas lentes estiveram voltadas para o que mais interessou nos dados.

Para estimular o raciocínio, construir nexos e relações, seria preciso compreender como as crianças estavam pensando, por isso o diálogo precisava continuar para aproximar pensamentos. A linguagem serviria como ponte entre maneiras diferentes de compreender os dados, mas sem impor.

Iniciamos o nosso segundo encontro com um diálogo sobre o que as crianças haviam visto na Dollar Street. Destacaram alguns pontos relacionados à variação e à generalização.

LUÍS - Professora, eu tinha visto uma casa toda assim (abre as duas mãos e as movimenta), assim de mendigo parece, toda desmontada. Ela tinha um ralo assim (gesticula abrindo as duas mãos) e bagunçada. É muito, muito ruim essa casa! 
PROFESSORA - É? E de onde era essa casa?

LUÍS - Era do Egito.

FÁBIO - Ah, no banheiro da minha casa também tem um buraco, o buraco pra sair a água...

SOFIA - Eu vi um monte de banheiros, todos tinham buraco.

Muitos riem, falam que o buraco serve pra sair o coco e o xixi.

LUCAS - Eu vi um buraco feito de metal.

(Trecho extraído do Diário de Campo 1, de 18/05/2019)

As crianças realizaram conexões entre os dados do mundo e suas próprias vidas. Comunicaram padrões percebidos, consequência da leitura entre os dados (CURCIO, 1994). Para falar sobre os dados, organizaram as informações e a classificação foi espontânea, a partir da categoria "um ralo no banheiro" citada por Luís, foram capazes de conectar a informação com sua realidade e generalizar que todos os banheiros têm buraco, apesar de seus materiais e formas poderem ser diferentes. Essa é uma característica da variação, que de acordo com Watson (2009), está presente na surpresa dos dados, no inesperado.

As crianças perceberam as diferenças entre os modos de vida das pessoas, mas também as semelhanças: há coisas, como "buracos de saída de água" muito parecidas em seu dia a dia. E é na semelhança que se estabelecem critérios comuns de classificação, "encontrar um critério comum a todos os elementos de um grupo é um processo de abstração de propriedades do objeto em função de uma delas" (CABRAL, 2016, p. 21). Assim, o banco de dados com imagens permite a surpresa causada pelo encontro com o outro, com o que é igual e diferente, outro que talvez não seja um total estranho levando em conta alguns aspectos do cotidiano.

De acordo com Gomes e Guimarães (2018), uma amostra é uma seleção que pretende representar a população e a "característica fundamental que determina a força de uma generalização estatística é a representatividade de amostra" (2018, p.137). A questão da representatividade da amostra incomodou as crianças porque não se sentiram representadas, queriam ver coisas conhecidas para testar a validade das informações, o que é possível no Google Maps, por exemplo, que trabalha com imagens globais.

Com a intenção de retomar a decepção causada pela amostragem e também para atender a outra categoria de Gal (2002) a fim de promover o letramento estatístico - saber de onde vem os dados - a professora contou a história dos criadores do banco de dados Dollar 
Street, mostrou suas fotografias, mostrou no mapa onde fica a Suécia (que é onde moram) e falou de suas motivações na criação do site. Nessa oportunidade, também mostrou a Rua Dólar no Datashow e explicou que ela é uma "amostra" da população mundial e que por ser amostra "não aparece tudo, são só pequenas partes escolhidas para o site porque o mundo é muito grande e não seria possível fotografar tudo e nem ver tudo". Fábio complementou dizendo que seria o "infinito de fotos, ele ia ficar tirando fotos até hoje". Utilizei tais palavras para que se familiarizassem com a linguagem estatística e com essa característica dos dados que estavam acessando. Ao mesmo tempo, tentei mostrar que a Rua Dólar é uma criação de algumas pessoas e essas pessoas também não sabem tudo, por isso não incluíram a cidade de Florianópolis.

Em seguida, a professora entregou uma folha para cada criança, ali elas teriam a tarefa de planejar o que gostariam de ver no Dollar Street. A tarefa pretendia trabalhar com uma grande quantidade de dados, pois é importante usar lentes de dados que, segundo English (2012), é saber olhar para uma categoria ou um atributo em específico, de acordo com os objetivos da investigação. Então, antes de ir aos computadores, as crianças decidiram o que queriam ver, qual era seu interesse. Sentadas em duplas para conversar, cada uma tinha sua tarefa individual.

Mariana e Vitória queriam ver coisas da casa como: gatinho, estante, vaso. Então a professora perguntou a elas que tipo de coisa é essa que queriam ver, elas não sabiam classificá-las. Perguntou se seria "decoração", disseram que não, até que encontraram uma palavra para generalizar as coisas que queriam ver: "enfeites".

Em seguida, as duas partiram para a escolha da localização do que queriam observar:

Figura 5 - Localização no mapa
MARIANA - eu quero ver o Brasil, vou marcar o Brasil.

VITÓRIA - Mas pra quê ver o Brasil, você já tá no Brasil!

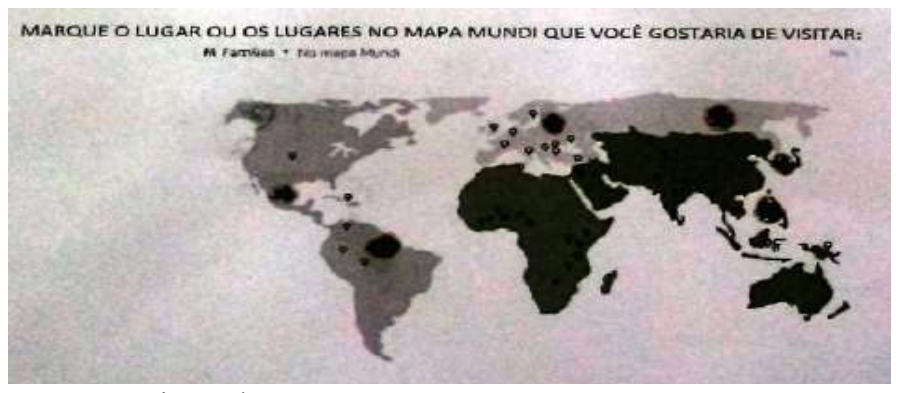

Fonte: Registro das autoras 
Depois, decidiram também ver gatinhos. No entanto, lembraram que não tem a categoria "gatinhos" e por isso escolhem "bichinho". Mariani escreveu "nifetix" para enfeites e Vitória registrou três categorias: cama, bichinhos e sala.

Figura 6 - Lentes de dados

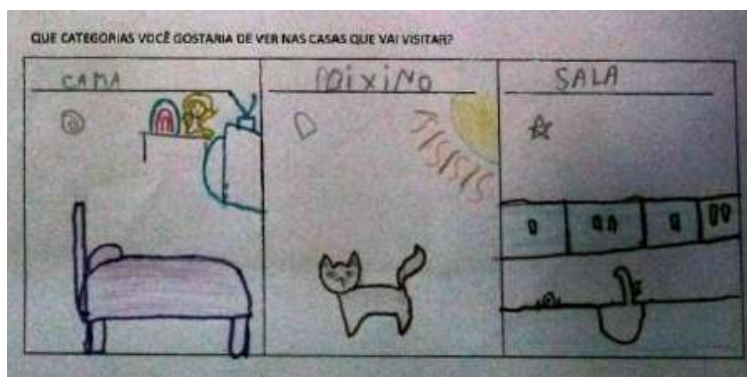

Fonte: Registro das autoras

Vitória lembrou que o banco de dados não tem a categoria "enfeites", então desenhou um quarto com enfeites e escreveu "cama", pois lembrou que é uma das categorias da Dollar Street.

Na sala informatizada, sentam lado a lado, cada uma em um computador, foram para o mapa do Dollar Street onde localizaram e escolheram a América. Depois, escolhem os quartos e salas na lista de categorias e ali encontraram os enfeites que queriam ver. Em seguida, foram aos animais de estimação. Mariana estava vendo cães e Victória diz:

VITORIA - Mas eu queria mesmo era ver uma gatinha - diz porque o ícone de "animais de estimação" é representado com a imagem de um cão.

MARIANA - Ali.

VITORIA - Gatinho! Tem gatinho!! Adorei esse gatinho, que fofo, fofinho - Ela fica surpresa porque vê gatinhos no mesmo ícone de "cão"

MARIANA - Ó um coelhinho!

VITORIA - Um gatinho pobre, coitadinho dele!

(Trecho extraído do Diário de Campo 1, de 18/05/2019)

Diante de tanta animação, num instante, havia metade da turma olhando os animais de estimação. Também queriam ver o "gatinho pobre" da Vitória. Perguntei a ela o que era um gatinho pobre e ela disse que "é um gatinho que tem uma casa com chão sem piso". A observação da menina diz que ela está compreendendo a forma de caracterizar o mundo a partir de fatos conforme refere Rosling (2020), que diz que uma das características que define uma família de nível 1 é o fato de não ter piso na casa. 
A exploração do site leva à realização de comparações. É quase inevitável uma visita sem que se definam critérios de comparação, sem que nossos olhos se voltem a algum ponto das realidades para comparar. De acordo com Cabral (2016), consciente ou não, a classificação faz parte do dia a dia. Está relacionada às escolhas que perpassam nossas vidas. No entanto, as comparações, bem como as escolhas (CABRAL, 2016), estão relacionadas a objetivos e necessidades específicas de cada indivíduo. Por isso, cada pessoa pode ver, classificar e interpretar os dados de maneira diferente.

O diálogo de Mariana e Vitória mostra que as duas tem intenções iniciais diferentes em relação ao que pretendem ver na Dollar Street. As diferentes perspectivas, ou seja, aquilo que escolhemos ver (ALRO; SKOVSMOSE, 2006) também podem ser chamadas de lentes de dados (ENGLISH, 2013) e se manifestam no uso da linguagem, naquilo sobre o que escolhemos falar e não falar, na forma como entendemos o outro. Apesar de cada uma ter seu foco um pouco diferenciado, a comunicação continuou unindo as duas, sendo que cada uma passou a ver e compreender a perspectiva da outra, tornando-se uma "perspectiva compartilhada" (ALRO; SKOVSMOSE, 2006). Olhar para a classificação do colega, que pode ser diferente da minha e tentar entendê-la também foi uma importante aprendizagem experimentada com a Dollar Street. Ao compreender a classificação do outro, olhamos para "o seu" modo de entender o mundo. Roazzi (1995) diz que a classificação é importante para a construção ativa da realidade, pois o ato de classificar nos leva a atribuir significado ao mundo.

No diálogo com diferentes perspectivas é que passamos a desenvolver o pensamento crítico como na fala "para que ver o Brasil se você já está no Brasil", que demonstra um entendimento para a finalidade da Dollar Street e a visão crítica diante do outro que pensa diferente. Na potencialidade do diálogo está implicado o pensar crítico: o diálogo implica um pensar crítico e também o gera, "sem ele não há comunicação e sem esta não há verdadeira educação" (FREIRE, 1987, p. 83).

Como o site é baseado em imagens e todas as palavras de busca são acompanhadas de ícones, Luís navegava sem ler as palavras e não sentiu a necessidade em mudar da língua 
inglesa para a língua portuguesa. O colega percebeu que o vizinho poderia ter sua vida facilitada se colocasse em português.

LUCAS - clica aqui e põe em Português

Luís clica, abre o menu e escolhe "português".

LUCAS - Olha aí "cumpade", coisas, casas, brinquedos, comida....

Luís vai passando uma por uma das categorias, lê em voz alta e clica para ver o que aparece:

Figura 7 - Registro das leituras de Luís

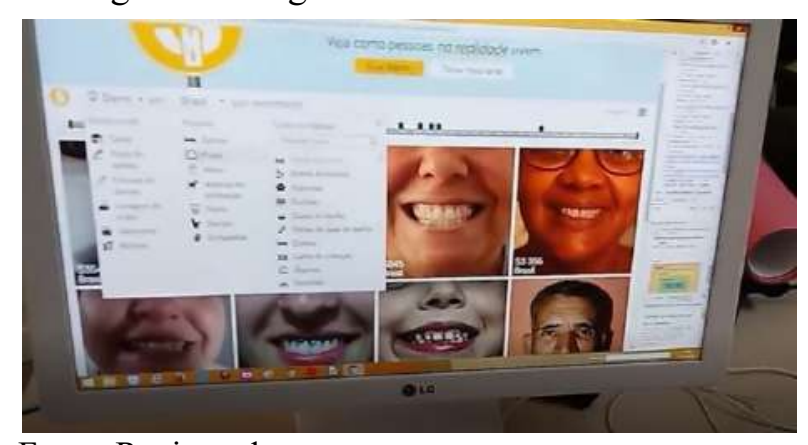

Fonte: Registro das autoras

- Den-tes, pi-so. Ah, o piso da casa!

(Trecho extraído do Diário de Campo 1 de 18/05/2019)

Alro e Skovsmose (2006) dizem que aprender é uma experiência pessoal que ocorre em contextos sociais repletos de relações interpessoais e isso manifesta-se na comunicação entre as pessoas. É possível observar o quanto o contexto e a abertura para o diálogo entre as crianças afetaram as possibilidades de aprendizagem: a conversa entre os dois meninos altera o curso, abre novos caminhos de pensamento. A tomada de consciência que acontece nesse diálogo mostra como o repertório de conceitos se expande a partir do intercâmbio entre as pessoas (FISHER, 2013).

O pequeno trecho de conversa demonstra a necessidade de diálogo entre as crianças mesmo na hora em que estão em comunicação com o mundo através das tecnologias. Os diálogos das crianças também mostram como a alfabetização no contexto do letramento pode acontecer no ambiente escolar quando se tem um ambiente de encontro entre as pessoas. Para Gal (2002), o sujeito letrado estatisticamente é capaz de avaliar uma informação estatística presente em qualquer contexto e argumentar com relação aos dados e seus fenômenos. Compreendemos que a definição do autor se dá como um ponto em que queremos chegar depois de percorrer um longo caminho. Mas pensamos que estamos no caminho e o nosso caminho percorre múltiplos contextos, representações e ativa a disposição em relação aos dados que seria, por exemplo, perceber que os dados do colega não estão apresentados em língua portuguesa e sentir-se disposto em agir em relação a isso. 
$\mathrm{Na}$ aula seguinte, a professora pediu que as crianças que explicassem como é a Dollar Street. Elas então falaram das muitas casas da rua e destacaram os animais de estimação e os nomes dos países visitados. Carolina diz ter encontrado uma tartaruga no ícone de cão.

CAROLINA - Lá na coisa de cachorrinho, eu vi uma tartaruga!

PROFESSORA - Mas como assim? Era coisa de cachorrinho e você viu tartaruga? (silêncio)

PROFESSORA - Que parte era aquela que você encontrou cachorrinho e também tartaruga?

ANA - É dos animais! - levanta-se e ergue os dois braços - são todos os bichos!!

PROFESSORA - Sim, são os animais de estimação.

(Trecho extraído do Diário de Campo 1 de 18/05/2019)

Figura 8 - Animais de estimação na Dollar Street
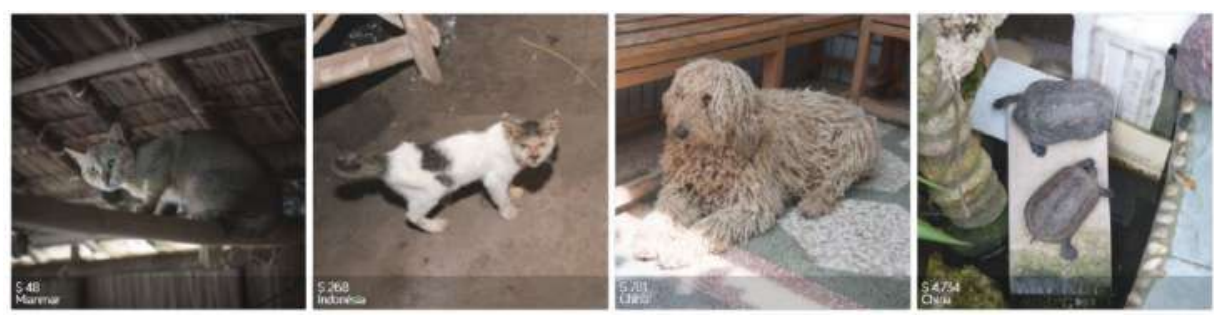

Fonte: https://www.gapminder.org/dollar-street/?topic=pets\&media=image

O diálogo mostra que Carolina não compreendeu a abrangência da categoria "animais de estimação", ou então leu o ícone (cão) mas não a escrita "animais de estimação", por isso estranhou ter tartaruga na imagem de "cachorrinho". No entanto, a colega percebeu que se tratava de incluir gatos, cães e tartarugas no mesmo grupo: animais de estimação. A partir desse diálogo, passamos escrever na lousa uma lista de animais de estimação que são representados e não representados na Rua Dólar.

Os diálogos nos levaram a questionar qual seria a realidade da rua em que se situava a escola das crianças e também a realidade do bairro: quais os animais de estimação que ocorrem e quantos? Nas aulas seguintes, organizamos gráficos e tabelas para poder compreender a ocorrência de animais no Dollar Street e depois comparar com os dados da rua da escola. Realizamos pesquisa de campo, produzimos formulários de entrevista, fomos à Rua da Escola para pesquisar e depois organizar os dados da nossa realidade imediata. As crianças foram inseridas no contexto estatístico e as estruturas estatísticas emergiram do contexto. Além disso, o processo de letramento estatístico esteve completamente relacionado à cultura letrada, 
contribuindo para os multiletramentos.

\section{REFLEXÕES FINAIS}

Esse trabalho nos deu pistas para responder nossa pergunta inicial sobre como desenvolver o letramento estatístico de forma que as crianças sejam protagonistas frente aos dados e estabeleçam conexões entre os dados da realidade e suas vidas.

Nas experiências de pesquisa em busca do letramento estatístico junto com as crianças vivenciamos momentos que nos mostraram o quanto os dados são necessários para a leitura do mundo. Esses momentos nos propiciaram a compreender como e por quem os dados são produzidos e a nos familiarizar com representações gráficas multivariadas. Além disso, palavras básicas da estatística descritiva, como amostra e intervalo passaram a fazer parte das conversas de sala de aula. Tais evidências nos mostram que nos anos iniciais do Ensino Fundamental é possível habitar o lugar de fronteira entre letramento e estatística, que nós crianças e professoras somos pessoas dispostas a ler, escrever, criar e imaginar com os dados.

Todo o trabalho consistiu numa investigação em estatística que foi sendo construída colaborativamente com as crianças, considerando e dando espaço aos seus interesses e movimentos. Esse processo foi livre, sem etapas pré-definidas e prontas, nem questões a priori. As perguntas surgiam e se modificavam pela ação das crianças na medida em que novas explorações surgiam no banco de dados. Essas explorações subsidiaram reflexões e novos questionamentos, que demandaram novas coletas de dados, tabulações, organizações, leituras e produção de estranhamentos.

Observamos que o ambiente aberto ao diálogo e sem verdades prontas e préestabelecidas é essencial para que o letramento estatístico aconteça. As crianças, quando vistas como pessoas capazes de andar pelos caminhos de análise de dados, se dispõem ao trabalho e "entram" na experiência estatística, vivem, se envolvem, revelando um espírito crítico que as fez inclusivamente colocar questões que se prendem com a representatividade da amostra, que no seu sentir não as representava.

A linguagem digital foi importante no sentido de que todos tiveram acesso interativo aos dados, podendo escolher caminhos de acordo com sua curiosidade e fazendo experimentações múltiplas que permitem observar variações e padrões. A característica do Dollar Street de usar imagens permitiu que todos tivessem acesso às informações, mesmo os 
que ainda não estavam alfabetizados. A exploração de dados multivariados permitiu que as crianças olhassem para os dados em diversas direções, podendo ter suas próprias escolhas de lentes de dados, conforme seus interesses.

Observamos que o que um sujeito letrado precisa aprender de estatística, que é complexo, mas está acessível às crianças. Os dados e suas formas de representação estão em constante movimento e, ainda, podem se encontrar em plataformas interativas para serem rearranjados de acordo com os interesses do leitor. Diante disso, é fácil compreender que aquilo que devemos ensinar para um cidadão letrado em estatística é muito mais do que gráficos e tabelas. Recordamos que Engel (1997, p. 46) evidencia essa realidade quando

afirma os dados da web podem consistir em uma variedade de formatos: imagens, texto, sons, datas, símbolos codificados e localizações e em uma variedade de contextos.

Esse trabalho nos levou a compreender o letramento estatístico não como um ponto de chegada, mas um caminho trilhado de forma conectada com as linguagens escrita, oral e digital. Vimos que o letramento estatístico é um caminho vivo, com diversas passagens, que precisa iniciar desde muito cedo e continuar seguindo, se ampliando ao longo da vida. Justo por ser um caminho de uma coisa que está em constante modificação, não é possível ensinar apenas com fórmulas prontas ou gráficos e tabelas prontos e bem organizados, mas requer ensinar para dar subsídios para compreensão do mundo com dados multivariados e assim desenvolver disposições estatísticas.

\section{REFERÊNCIAS}

ALRO, H; SKOVSMOSE, O. Diálogo e Aprendizagem Em Educação Matemática. Belo Horizonte: Autêntica, 2006.

BATANERO, C.; DÍAZ, C.; CONTRERAS, J. M. ROA, R. El sentido estadístico y su desarrollo. Revista Didáctica de las Matemáticas. Volume 83, páginas 7-18, julho de 2013. BEN-ZVI, D. Foreword. In: Leavy, A., Meletiou-Mavrotheris, M., \& Paparistodemou, E. (Eds.). Statistics in Early Childhood and Primary Education: Supporting early statistical and probabilistic thinking. Springer, Singapore, 2018. p.vii-viii.

CABRAL, P. C. M. Aprender a classificar nos anos iniciais do Ensino Fundamental. Mestrado em Educação Matemática e Tecnológica. Universidade Federal de Pernambuco. Recife, 2016. Disponível em https://repositorio.ufpe.br/handle/123456789/22284

CURCIO, F. R. Developing Graph Comprehension: elementar and middle school activities. 2nd prt. USA: National Council of Teachers of Mathematics, 1994

DOLLAR STREET: Banco de Dados. Disponível em https://www.gapminder.org/dollar- 
street/matrix Acessado em 07 de outubro de 2020.

ENGEL, J. Statistical Literacy for active Citizenship: A Call for Data Science Education. Statistics Education Research Journal, 16(1), pp.44-49, 2017.

ENGLISH, L. D. Data modelling with first-grade students. Educational Studies in Mathematics, v. 81, n. 1, p. 15-30, 2012. Disponível em http://eprints.qut.edu.au/48400/

ENGLISH, L. D. Reconceptualizing Statistical Learning in the Early Years. In Early Mathematics Learning. Advances in Mathematics Education. Springer, 2013, 67-82.

FREIRE, Paulo. Pedagogia do Oprimido. 17ed. Rio de Janeiro: Paz e Terra, 1987.

FISHER, R. Diálogo creativo: hablar para pensar en el aula. Madrid: Morata, 2013.

GAL, I. Adult's Statistical Literacy: meanings, components, responsibilities. International Statistical Review, v. 70, n. 1, p. 1-25, 2002. Disponível em https://onlinelibrary.wiley.com/doi/10.1111/j.1751-5823.2002.tb00336.x

GOMES, T. M. S.; GUIMARÃES, G. L.; Compreensão dos estudantes do ensino fundamental sobre seleção de uma amostra representativa. Com a Palavra o Professor, Vitória da Conquista, v.3, n.2, mai/ago. 2018. Disponível em http://revista.geem.mat.br/index.php/CPP/article/view/211

LOPES, C. E.; COX, D. The impact of culturally responsive teaching on statistical and probabilistic learning of elementary children. In: Statistics in Early Childhood and Primary Education. Springer, Singapore, 2018. p. 75-88. Disponível em https://link.springer.com/chapter/10.1007/978-981-13-1044-7_5

MAKAR, Katie. Theorising links between context and structure to introduce powerful statistical ideas in the early years. In: Statistics in Early Childhood and Primary Education. Springer, Singapore, 2018. p. 3-20.

MOORE, D. Uncertainty. In L. Steen (Ed.), On the shoulders of giants: New approaches to numeracy (pp. 95-137). Washington, DC: The National Academies Press, 1990

ROSLING, H.; ROSLING, O.; ROSLING, A. R. Factfulness: o hábito libertador de só ter opiniões baseadas em fatos. 4ed. Rio de Janeiro: Record, 2020.

WATSON, J. Statistical Literacy at School: growth and goals. Mahwah, New Jersey: Lawrence Erlbaum Associates, 2006.

WATSON, J. The influence of variation and expectation on the developing awareness of distributions. Statistics Education Research Journal, 8(1), 32-61, 2009. Disponível em http://www.stat.auckland.ac.nz/serj

Submetido em 14 de novembro de 2020. Aprovado em 21 de janeiro de 2021. 